\title{
Total Synthesis of Nannocystin Ax
}

\author{
Caroline Poock ${ }^{\dagger}$ and Markus Kalesse $e^{* \dagger, \dagger}$.
}

${ }^{\dagger}$ Institute for Organic Chemistry and Centre of Biomolecular Drug Research (BMWZ) Leibniz Universität Hannover, Schneiderberg 1B, D-30167 Hannover, Germany

${ }^{\star}$ Helmholtz Centre for Infection Research (HZI), Inhoffenstrasse 7, D-38124 Braunschweig, Germany

Supporting Information Placeholder

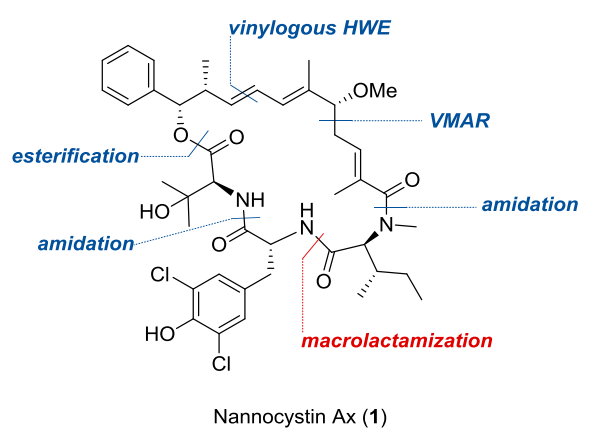

\begin{abstract}
The total synthesis of nannocystin Ax with an overall yield of $11 \%$ and 14 steps as the longest linear sequence is reported. Nannocystin Ax is a cytotoxic 21-membered depsipeptide and was isolated from the myxobacterial genus Nannocystis $s p$. The synthesis uses a vinylogous Horner-Wadsworth Emmons reaction (HWE) and a vinylogous Mukaiyama aldol reaction (VMAR) as the key steps for the construction of the polyketide fragment. The macrocycle was closed via a macrolactamization reaction using $\mathrm{COMU}^{\circledR}$.
\end{abstract}

Natural products are a major source for drugs used in the treatment of various diseases. They have been particularly successful as antibiotics or as anti-cancer agents. ${ }^{1}$ An important source for those secondary metabolites are myxobacteria from which a variety of structurally different compounds with diverse biological activities and unique modes of action have been isolated. ${ }^{2,3}$ Recently the groups of Hoepfner (Novartis) ${ }^{4}$ and Brönstrup (Sanofi) $)^{5}$ isolated a new family of 21-membered macrocyclic depsipeptides, from the myxobacterial genus Nannocystis sp. All members of the nannocystin family consist of a polyketide and a tripeptide hemisphere. Differences are present in the peptidic parts as well as in the presence of the $\alpha, \beta$-epoxyamide moiety, which is present in nannocystin A (2), but not in nannocystin Ax (1) (Figure 1). Studies on the biological activity showed that all isolated compounds bear an antiproliferative activity against various cancer cell lines in the nanomolar range $\left(\mathrm{IC}_{50} 2.6 \mathrm{nM}^{4}\right.$ respectively $0.6 \mathrm{nM}^{5}$ for (2); $\mathrm{IC}_{50} 5.4 \mathrm{nM}$ for (1); HCT-116) and that the epoxide does not seem to be part of the pharmacophore. As primary target for the nannocystins the eukaryotic translation elongation factor $1 \alpha(\mathrm{EF}-1 \alpha)$ was proposed. Overexpression of EF-1 $\alpha$ is observed in various cancer cells, ${ }^{6}$ but its role in tumor biology still remains unclear. While several studies claim anti-apoptotic properties and a negative influence for chemotherapy ${ }^{7}$ other studies propose pro-apoptotic properties. ${ }^{8,9}$ However, a correlation
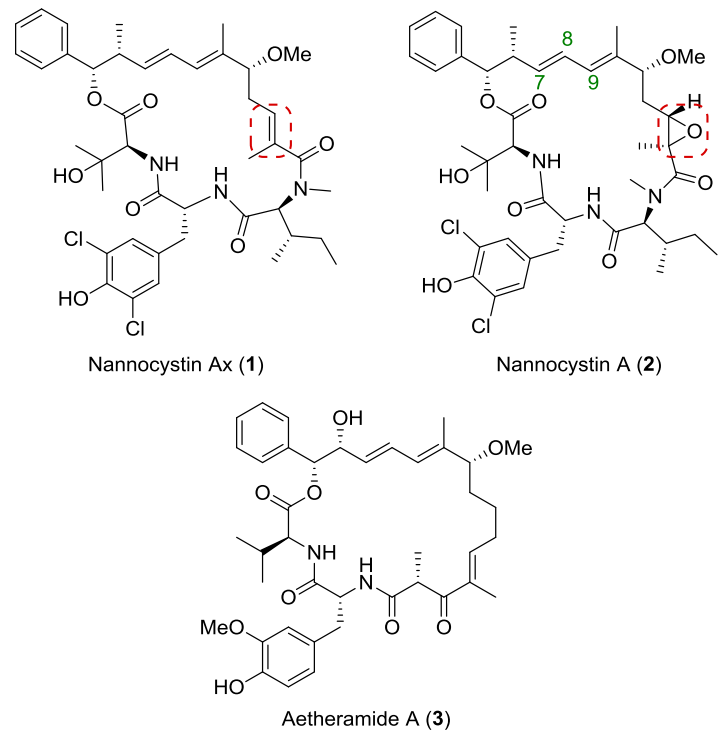

Figure 1. Structures of nannocystin A (2), Ax (1) and aetheramide A (3).

between overexpression of EF-1 $\alpha$ and a negative prognosis for gastric cancer has been shown by Yang. ${ }^{10}$ These findings make the nannocystins interesting candidates for the development of new drugs. Consequently, it is not surprising that several groups contributed to the field of nannocystins. Four total syntheses of nannocystin A (2) have been achieved by the 
groups of Wang, ${ }^{11} \mathrm{Ye}^{12} \mathrm{Chen}^{13}$ and $\mathrm{He},{ }^{16 \mathrm{c}}$ and one of nannocystin Ax (1) by the group of Liu. ${ }^{14}$ Also, the structurally related depsipeptides aetheramides A (3) (Figure 1) and B were recently synthesized in our laboratories ${ }^{15}$ and in the groups of Guo, $\mathrm{He}^{16}$ and Prasad. ${ }^{17}$ In the context of our program to establish syntheses for complex polyketidal natural products we aimed at synthesizing nannocystin $\mathrm{Ax} .{ }^{18}$

Our retrosynthetic approach (Scheme 1) for the synthesis of nannocystin Ax (1) is based on the division in a polyketide and a tripeptide segment. We envisioned to close the macrocycle via a macrolactamization between the tyrosine and isoleucine part. This represents a new approach for closure of the macrocycle compared to the other published total syntheses of nannocystines. In those syntheses a cross coupling between $\mathrm{C} 8$ and $\mathrm{C} 9^{12,13,14}$ or a metathesis between $\mathrm{C} 7$ and $\mathrm{C} 8{ }^{11}$ was performed. The linear precursor could be generated from northern fragment $\mathbf{4}$ and the three peptide fragments $\mathbf{6}, \mathbf{7}$ and $\mathbf{8}^{19}$ via sequential amidation or esterification reactions. The key steps for the synthesis of northern fragment 4 were a vinylogous Horner-Wodsworth-Emmons reaction ${ }^{15}$ (HWE) and an asymmetric vinylogous Mukaiyama aldol reaction (VMAR) ${ }^{20}$ to install the $\mathrm{C} 11$ stereocenter.

Scheme 1. Retrosynthetic Analysis.

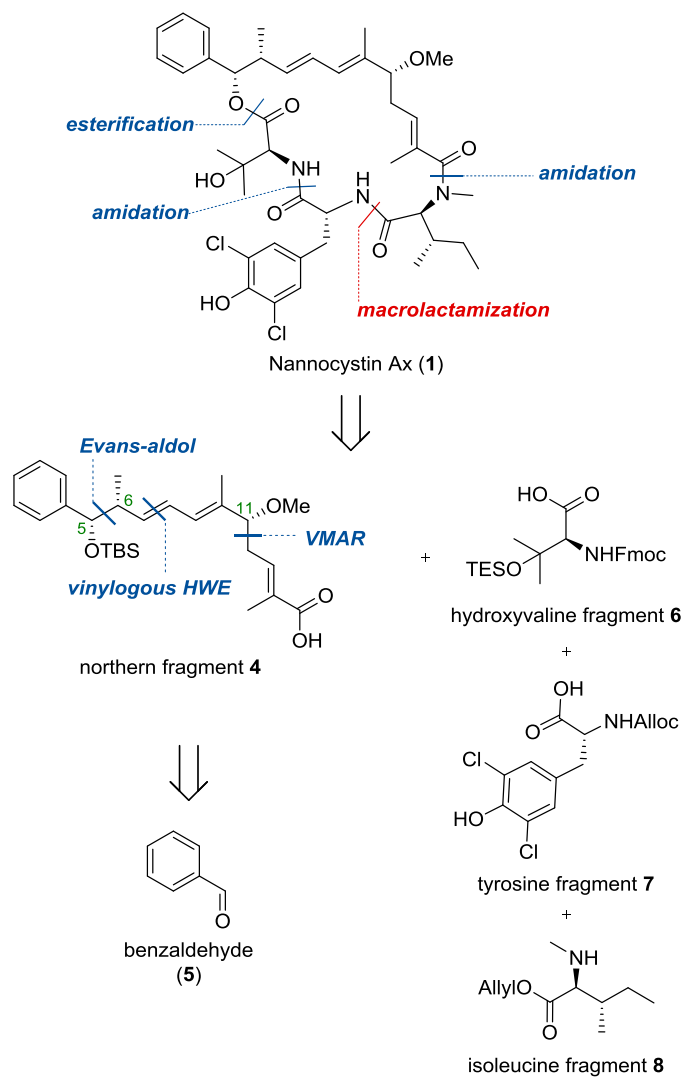

For the synthesis (Scheme 2) of northern fragment 4 benzaldehyde (5) was converted into literature known aldehyde $\mathbf{9}^{21}$ in four steps utilizing an Evans aldol reaction to install the stereocenters at $\mathrm{C} 5$ and C6. Afterwards, a vinylogous Horner-Wadsworth-Emmons ${ }^{15}$ olefination with phosphonate $\mathbf{1 2}^{22}$ provided the desired acrylic ester in very good yield and with good E/Z-ratio of 5.6:1 in favor of the desired $\mathrm{C} 7 / \mathrm{C} 8-E$-Isomer. After a reduction-oxidation sequence aldehyde 10 was submitted to the vinylogous Mukaiyma aldol reaction with TES-ketene acetal $\mathbf{1 3}$ using a protocol developed in our group which uses a chiral oxazaborolidinone Lewis acid, generated in situ from $N$-Ts-L-tryptophane and dichlorophenylborane. ${ }^{20}$ Coordination between the aldehyde and the chiral Lewis acid leads to attack from the less hindered re-face of the aldehyde, giving preferentially the $(R)$-configured hydroxy group at C11. Alcohol 11 was obtained in good yield but moderate diastereoselectivity (3.1:1) for the desired product. Unfortunately, the undesired diastereoisomer could not be fully separated at this stage, but was removed during further steps. Finally, the hydroxy function of $\mathbf{1 1}$ was converted to the corresponding methyl ether and the ethyl ester was hydrolized, providing the northern fragment 4 . The acid was directly used in the next step, as it was not stable upon storage.

\section{Scheme 2. Synthesis of the northern fragment 4.}
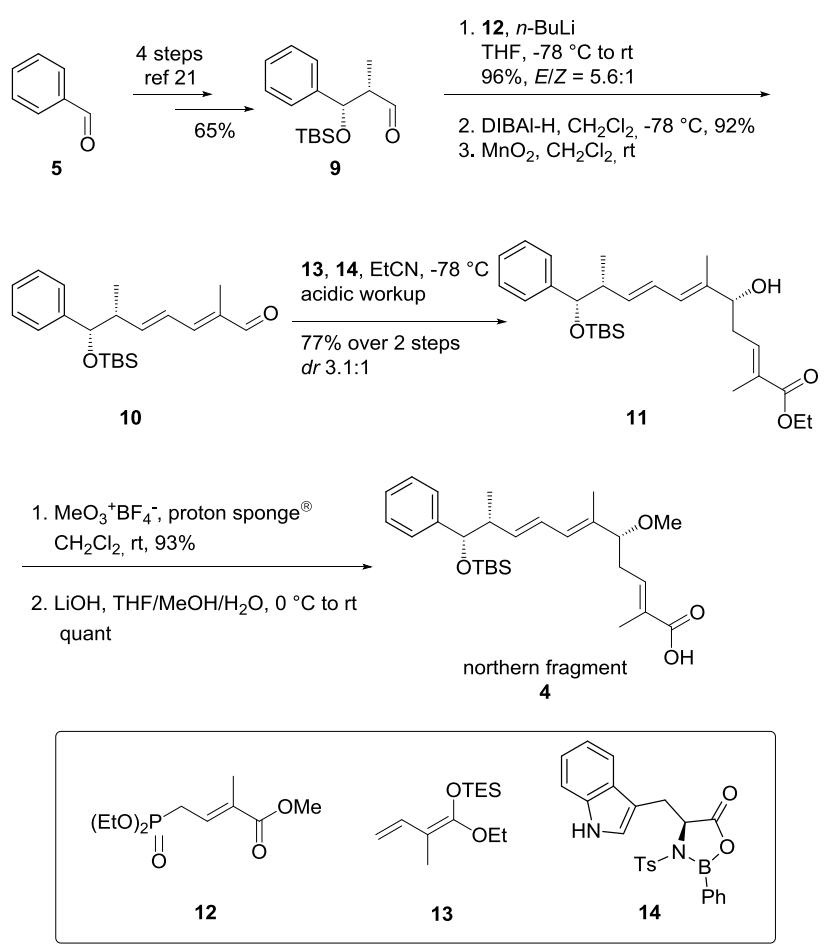

The synthesis of $\beta$-hydroxyvaline fragment 6 (Scheme 3) started from known $N$-Boc-L- $\beta$-hydroxyvaline (16) which is commercially available but could also be synthesized starting from D-serine (15) using a literature known protocol. ${ }^{23}$ Afterwards, the carboxylic acid was protected as a benzyl ester, the amine protecting group was changed from Boc to Fmoc and the tertiary alcohol was protected as TES ether. The benzyl group was then cleaved via hydrogenation. Tyrosine fragment 7 (Scheme 3) was synthesized by Alloc protection of known 3,5-dichloro-D-tyrosine (18). ${ }^{24}$ Isoleucine fragment 8 can be obtained from L-isoleucine using the literature procedure. $^{19}$ 
Scheme 3. Synthesis of peptide fragments 6 and 7.
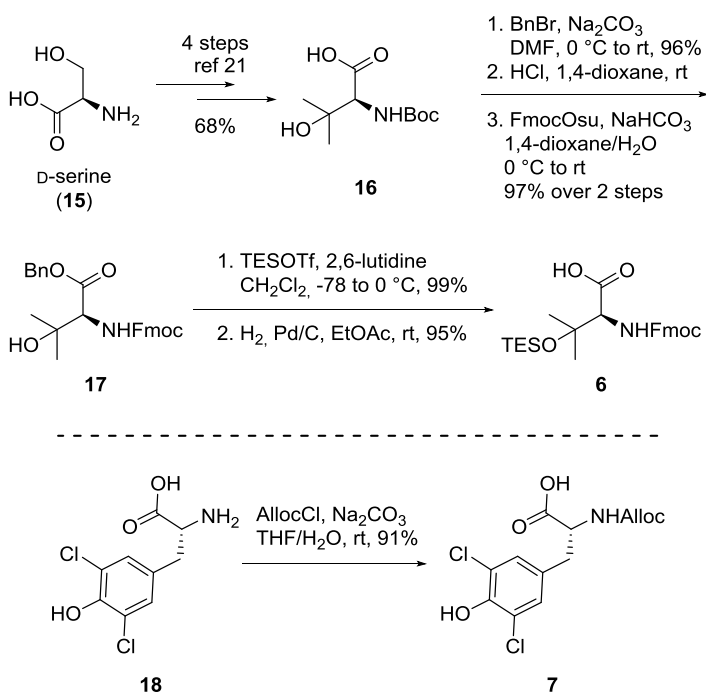

Amidation between northern fragment $\mathbf{4}$ and isoleucine fragment 8 (Scheme 4) proved to be challenging due to the presence of the $N$-methylated amine. ${ }^{25}$ For this coupling several conditions were investigated (e.g. PyBrop, PyClop, Oxyma, EDC $\cdot \mathrm{HCl}$ and DMAP), finding that $\mathrm{COMU}^{\circledR}$ ((1-Cyano-2-ethoxy-2-oxoethylidenaminooxy)dimethylaminomorpholino-carbenium hexafluorophosphate $)^{26}$ gave best results $(82 \%)$ for this substrates. We also tried to apply these conditions to a di- and tripeptide fragment, but were not able to isolate the desired products. After removal of the TBS protecting group with TBAF esterification of the obtained alcohol 18 with hydroxyvaline fragment 6 was achieved. For this it was necessary to protect the tertiary alcohol of $\mathbf{6}$, preventing it from elimination. Regrettably, only $60 \%$ of the desired ester 19 was isolated. Fortunately, most of alcohol 18 could be recovered from the reaction, whereas this was not possible for hydroxyvaline fragment 6 . Removal of the Fmoc protecting group enabled amidation with tyrosine fragment 6 using HOBt and EDC $\cdot \mathrm{HCl}$. On a small scale $(20 \mu \mathrm{mol})$ a good yield of $77 \%$ was obtained, whereas we observed a drop in yield during scale up $(\sim 0.1 \mathrm{mmol})$ as well as formation of diastereoisomers $(60 \%, d \mathrm{r} \sim 2: 1)$. After simultaneous removal of the Allyl- and Alloc-group we were able to perform the macrolactamization using $\mathrm{COMU}^{\circledR}$, yielding the macrocycle in $66 \%$ yield. Deprotection of the tertiary TES ether with TBAF leads to nannocystin Ax (1) in good yield.

In conclusion, the total synthesis of nannocystin Ax (1) with a longest linear sequence of 14 steps and an overall yield of $11 \%$ starting from building block 9 has been accomplished. In contrast to the other published total syntheses of nannocystin A (2) $)^{11,12,13}$ and Ax (1) ${ }^{14}$ our synthesis closed the macrocycle via an amidation reaction instead of cross coupling or a metathesis. The stepwise introduction of the three peptide fragments in our approach could allow incorporation of modified fragments, in order to provide derivatives which could be used for further biological investigations.

\section{Scheme 4. Endgame of the Total Synthesis.}
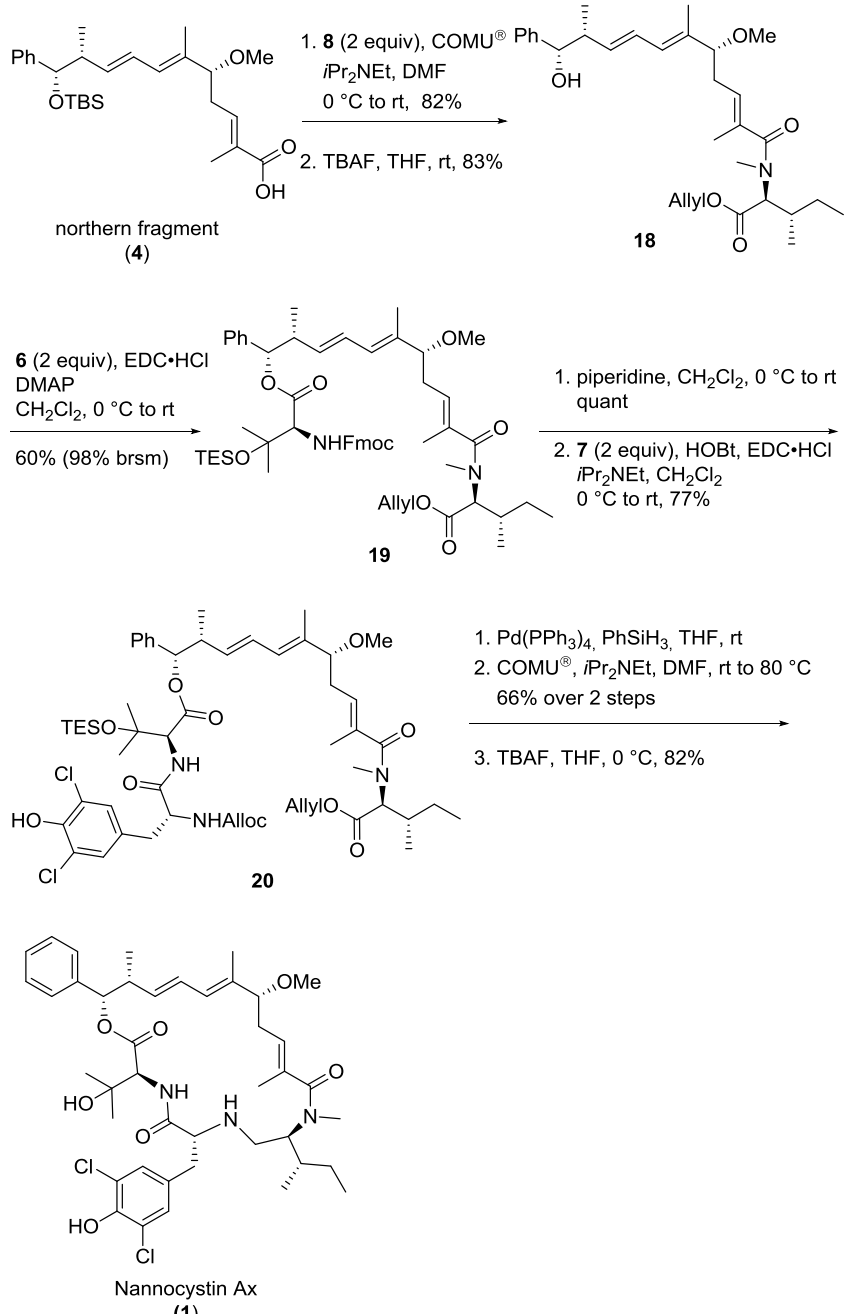

(1)

\section{ASSOCIATED CONTENT}

\section{Supporting Information}

The Supporting Information is available free of charge on the ACS Publications website.

Experimental procedures and spectral data of compounds described herein (PDF)

\section{AUTHOR INFORMATION}

\section{Corresponding Author}

*E-mail: markus.kalesse@oci.uni-hannover.de.

\section{Author Contributions}

All authors have given approval to the final version of the manuscript.

Notes

The authors declare no competing financial interest.

\section{ACKNOWLEDGMENT}


We acknowledge the spectroscopy department of the Institute of Organic Chemistry for their support. Furthermore, we thank Dr. Phillip Krastel (Novartis Institutes for BioMedical Research) for providing the NMR spectrum of natural nannocystin Ax.

\section{REFERENCES}

(1) Borchart, J. K. Drug News Perspect. 2002, 15, 187-192.

(2) (a) Reichenbach, H. J. Ind. Microbiol. Biot. 2001, 27, 149-157. (b)

Herrmann, J.; Abou Fayadab, A.; Müller, R. Nat. Prod. Rep. 2017, 34, 135-160.

(3) Dawid, W. FEMS Microbiol. Rev. 2000, 24, 403-427.

(4) Krastel, P.; Roggo, S. Schirle, M.; Ross, N. T.; Perruciu. F.; Aspesi Jr., P.; Aust, T.; Buntin, K.; Estoppey, D.; Liechti, B.; Mapa,

F.; Memmert, K.; Miller, H.; Pan, X.; Riedel, R.; Thiebaut, C.; Thosa, J.; Wagner, T.; Weber, E.; Xie, X.; Schmitt, E. K.; Hoepfner, D. Angew. Chem. Int. Ed. 2015, 54, 10149-10154.

(5) Hoffmann, H.; Kogler, H.; Heyse, W.; Matter, H.; Caspers, M.; Schummer, D.; Klemke-Jahn, C.; Bauer, A.; Penarier, G.; Debussche, L.; Brönstrup, M. Angew.Chem. Int. Ed. 2015, 54, 10145-10148.

(6) Abbas, W.; Kumar, A.; Herbein, G. Front. Oncol. 2015, 5: 75. (7) (a) Mohler, J. L; Morris, T. L.: Ford III, O. H.; Alvey, R. F., Sakamoto, C.; Gregory, C. W. Prostate 2002, 51, 247-255. (b) de Wit, N. J.; Burtscher, H. J.; Weidle, U. H.; Ruiter, D. J.; van Muijen, G. N. Melanoma Res. 2002, 12, 57-69. (c) Johnsson, A.; Zeelenberg, I.; Min, Y.; Hilinski, J.; Berry, C.; Howell, S. B.; Los, G. Br. J. Cancer 2000, 83, 1047-1054.

(8) Duttaroy, A.; Bourbeau, D.; Wang, X. L.; Wang, E. Exp. Cell Res. 1998, 238, 168-176.

(9) Blanch, A.; Robinson, F.; Watson, I. R.; Cheng, L. S.; Irwin, M. S. PLOS ONE 2013, 8: e66436.

(10) Yang, S.; Lu, M.; Chen, Y.; Meng, D.; Sun, R.; Yun, D.; Zhao, Z.; Lu, D.; Li, Y. J. Cancer Res. Clin. Oncol. 2015, 141, 1265-1275. (11) Huang, J.; Whang, Z. Org. Lett. 2016, 18, 4702-4705.

(12) Liao, L.; Zhou, J.; Xu, Z.; Ye, T. Angew. Chem. Int. Ed. 2016, $55,13263-13266$.

(13) Yang, Z.; Xu, X.; Yang, C.-H.; Tian, Y.; Chen, X.; Lian, L.; Pan, W.; Su, X.; Zhang, W.; Chen, Y. Org. Lett. 2016, 18, 5768-5770. (14) Zhang, Y.-H.; Liu, R.; Liu, B. Chem. Comm. 2017, 53, 55495552 .

(15) Gerstmann, L.; Kalesse, M. Chem. Eur. J. 2016, 22, 1121011212.

(16) (a) Qi, N.; Wang, Z.; Allu, S. R.; Liu, Q.; Guo, J.; He, Y. Org. Lett. 2016, 18, 4718-4721. (b) Qi, N.; Allu, S. R.; Wang, Z.; Liu, Q.; Guo, J.; He, Y. J. Org. Chem. 2016, 81, 12466-12471. (c) Liu, Q.; Hu, P.; He, Y. J. Org. Chem. 2017, 82, DOI: 0.1021/acs.joc.7b01502. (17) Revu, O.; Prasad, K.R. J. Org. Chem. 2017, 82, 438-460.
(18) (a) Brodmann, T.; Janssen, D.; Kalesse, M. J. Am. Chem. Soc. 2010, 132, 13610-13611. (b) Diaz, N.; Zhu, M.; Ehrlich, G.; Eggert, U.; Muthukumar, Y.; Sasse, F.; Kalesse, M. Chem. Eur. J. 2012, 18, 4946-4952. (c) Jahns, C.; Hoffmann, T.; Müller, S.; Gerth, L.; Washausen, P.; Höfle, G.; Reichenbach, H.; Kalesse, M.; Müller,R. Angew. Chem. Int. Ed. Engl. 2012, 51, 5239-5243. (d) Hartman, O.; Kalesse, M. Org. Lett. 2012, 14, 1608-1611. (e) Rentsch, A.; Kalesse, M. Angew. Chem. Int. Ed. 2012, 51, 11381-11384. (f) Symkenberg, G.; Kalesse, M. Angew. Chem. Int. Ed., 2014, 53, 1795-1798. (g)

Gieseler, M. T.; Kalesse, M. Org. Lett. 2014, 16, 548-551. (h)

Hartmann, O.; Kalesse, M. Angew. Chem. Int. Ed. 2014, 53, 73357338. (i) Tautz, T.; Hoffmann, J.; Hoffmann, T.; Steinmetz, H.; Washausen,P.; Kunze, B.; Huch, V.; Kitsche, H.; Reichenbach, H.; Höfle, G.; Müller, R.; Kalesse, M. Org. Lett. 2016, 18, 2560-2563. (j) Steinmetz, H.; Li, J.; Fu, C.; Zaburannyi, N.; Kunze, B.; Harmrolfs, K.; Schmitt, V.; Herrmann, J.; Reichenbach, H.; Höfle, G.; Kalesse, M.; Müller, R. Angew. Chem. Int. Ed. 2016, 55, 10113-10117.

(19) Srinivas, A.; Sunitha, M.; Rao, C. G. Acta Chim. Slov. 2016, 63, 344-350.

(20) Simsek, S.; Horzella, M.; Kalesse, M. Org. Lett. 2007, 9, 56375639.

(21) Schläger, N., Kirschning, A. Org. Biomol. Chem. 2012, 10, 7721-7729.

(22) Rainer, J. D.; Wang, J.; Boyarskikh, V. Org. Lett. 2011, 13, 700702 .

(23) Lubell, W. D.; Dettweiler, J. E. J. Org. Chem. 2003, 68, 177-179. (24) Golakoti, T.; Ogino, J.; Heltzel, C. E.; Le Husebo, T.; Jensen, C. M.; Larsen, L. K.; Patterson, G. M. L.; Moore, R. E.; Mooberry, S. L.; Corbett, T. H.; Valeriote, F. H. J. Am. Chem. Soc. 1995, 117, 1203012049.

(25) (a) Chamberlin, R. A.; Humphrey, J. M. Chem. Rev. 1997, 97, 2243-2266. (b) Coste, J.; Frèrot, E.; Jouin, P. J. Org. Chem. 1994, 59, 2437-2446.(26) (a) El-Faham, A.; Funosas, R. S.; Prohens, R.; Albericio, F. Chem. Eur. J. 2009, 15, 9404 - 9416. (b) El-Faham, A.; Albericio, F. J. Peptide Sci. 2010, 16, 6-9. (c) Subirós-Fuonosas, R.; Nieto-Rodriguez, L.; Jensen, K. J.; Albericio, F. J. Peptide Sci. 2013, 19, 408-414. 